\title{
FORMULAE FOR AFFERENT AND EFFERENT ARTERIOLAR RESISTANCE IN THE HUMAN KIDNEY: AN APPLICATION TO THE EFFECTS OF SPINAL ANESTHESIA
}

\author{
BY HAROLD LAMPORT \\ (From the Department of Neurology, College of Physicians and Surgeons, \\ Columbia University and The Neurological Institute, New York City)
}

(Received for publication May 21, 1941)

Glomerular dynamics are steadily becoming more comprehensible as the trenchant methods for studying renal physiology developed by Homer Smith and his coworkers $(1,2)$ are further extended. Their recent analysis of the problem, using the current conception of the glomerulus as a pure ultra-filter operated by the hydrostatic pressure of the blood, is based on various presumptions-some of them explicit and supported by evidence, others tacit or not supported by evidence (2).

An examination of these basic questions leads to formulae, different in certain respects from those developed by these workers, which can be applied clinically to determine the actual afferent and efferent arteriolar resistance of human kidneys. We shall first present these formulae, with an example of a clinical application, before proceeding much further with their detailed derivation.

Fundamentally, the essence of a quantitative description of resistance, whether applied to flow of fluid or electricity, is the representation of resistance in terms of flow and pressure, the customarily measured quantities. In electricity, Ohm's law defines resistance as the ratio of the potential drop, in volts, along the resistor, to the electric current flow in it, in amperes. In hydraulics, Poiseuille, who was brought to the problem by his interest in the resistance of the blood vessels to the circulation of the blood, has similarly defined resistance as the ratio of the fall in pressure from one end to the other of a continuous wetted tube, to the rate of flow through it, after being multiplied by the viscosity of the fluid. Thus:

$$
\text { Resistance }=\frac{\text { drop in pressure }}{\text { rate of flow } X \text { viscosity }} \text {. }
$$

It is, of course, applicable in the simple form only if certain conditions are fulfilled. For ex- ample, it is presumed that the flow into the resistance is the same as the outflow: there are no leaks. In the discussion of the derivation of our formulae, the matter of the applicability and modification of Poiseuille's law and the validity of the choice of the points along the kidney's vascular system between which resistance is to be measured will be of importance. Approximations for the changes in viscosity of the blood will also be offered and supported. For this purpose, empirical formulae are to be derived which will relate the viscosity of plasma and whole blood to the serum protein content and hematocrit.

By itself, Poiseuille's law may not be directly applied to renal afferent and efferent arteriolar resistance. One must add the hypothesis, well supported by Homer Smith et al. (2), and which represents currently accepted views on the kidney's function, that in the glomerular capillaries the pressure of the blood filters out non-protein fluid into Bowman's capsule until finally the opposing osmotic force of the blood proteins thereby concentrated rises to equal it. This fluid then becomes the raw material from which the kidney's tubules elaborate urine. In the glomerulus, the filtrate is osmotically in equilibrium, across the capillary membrane, with the blood as it starts to enter the efferent arteriole.

This hypothesis of osmotic equilibrium, like Poiseuille's law, is subject to quantitation. Knowing the degree of increased concentration of the blood proteins produced by glomerular filtration, we can estimate from an empirical equation the resulting increased osmotic pressure and, therefore, the blood pressure in the terminal portion of the glomerular capillaries. In this way, we obtain one of the pressure measurements needed to apply Poiseuille's law to the kidney.

The rates of flow of blood and of glomerular 
filtration are determined, clinically, by means of the diodrast and inulin clearances (1).

\section{PART I}

\section{Formulae}

The final formulae developed require definitions of certain symbols. We shall give them here briefly; they are more exactly defined in Part II.

Let $R_{\Lambda}=$ resistance of afferent arterioles in $\mathrm{mm}$. $\mathrm{Hg}$ per cc. per minute.

$\boldsymbol{R}_{\boldsymbol{E}}=$ resistance of efferent arterioles in $\mathrm{mm} . \mathbf{H g}$ per cc. per minute.

$R=R_{A}+R_{B}$, total resistance of renal arterioles in $\mathrm{mm}$. $\mathrm{Hg}$ per cc. per minute.

$I=$ inulin clearance in cc. per minute.

$D=$ diodrast clearance in cc. per minute.

$F=\frac{I}{D}$, the filtration fraction.

$S=$ grams of protein in 100 cc. serum.

$H_{c}=$ hematocrit, as a fraction of 1 .

$H=\frac{I}{1-H_{c}}$.

$k=a$ constant dependent on the hematocrit. For all, except grossly abnormal hematocrits, $k=0.47$.

$\boldsymbol{P}_{\boldsymbol{y}}=$ mean of systolic and diastolic brachial blood pressures in $\mathrm{mm}$. $\mathrm{Hg}$ of the recumbent subject.

Where

$$
\begin{gathered}
P_{O}=\frac{2.34 S}{1-0.0542 S} \text { and } P_{O^{\prime}}=\frac{2.34 S}{1-0.0542 S-F}, \\
R_{\Lambda}=\frac{P_{M}-P_{O^{\prime}}-40}{H D}, \\
R_{E}=\frac{(1-k F)\left(P_{O^{\prime}}-P_{O}+10\right)}{H D}
\end{gathered}
$$

or

$$
R_{E}=\frac{(1-0.47 F)\left(P_{0^{\prime}}-P_{O}+10\right)}{H D}
$$

For normal subjects, such as those reported by Smith and his coworkers (3), the formulae can be simplified. Using the average hematocrit of 43 per cent ${ }^{1}$; serum protein as 7 grams per $100 \mathrm{c}$., with an osmotic pressure of the corresponding plasma of $26.4 \mathrm{~mm}$. $\mathrm{Hg}$, the formulae become

$$
R_{\Lambda}=\frac{P_{M}-P_{O^{\prime}}-40}{1.755 D} ; R_{E}=\frac{(1-0.47 F)\left(P_{O^{\prime}}-16.4\right)}{1.755 D}
$$

\section{Clinical application}

We shall now proceed to exemplify the use of these formulae in clinical material. There has been considerable discussion as to the part man's renal nerves play in controlling blood flow through the kidneys. On the assumption that spinal anesthesia abolishes any possible neuro-

\footnotetext{
1 Dr. Homer Smith has very kindly supplied this datum.
}

genic control of the kidneys, Smith and his collaborators (3) have examined the changes produced in diodrast and inulin clearances and in blood pressure in a series of normal, basal, supine subjects. They have reached the conclusion that the kidneys are "not dependent upon tonic activity of the central nervous system."

Examining their cases, as reported, we omit, as does Smith, any correction factor for diodrast clearance. We use the set of simpler formulae above, as individual hematocrit and serum protein are not recorded. The results of this application are given in Table $\mathrm{I}$.

The average fall in renal arteriolar resistance is found to be $\mathbf{3 2}$ per cent with a probable error of 4.2 per cent. Although so large a change may be due solely to autonomous activity of the denervated kidneys, it has not been demonstrated that abolition of central nervous influence is not involved. An analysis of data on blood pressure and cardiac output before and during spinal anesthesia in 11 cases, using the Poiseuille law formula with $20 \mathrm{~mm}$. correction subtracted from mean blood pressure, ${ }^{2}$ shows no consistent change in total body vascular resistance $(4,5)$. Consequently, a 32 per cent fall in renal arteriolar resistance would appear significant.

The afferent arterioles always dilated; the average is 70 per cent fall in resistance. ${ }^{3}$ The afferent arteriolar resistance always fell more than the efferent arteriolar resistance. The efferent arteriolar resistance fell in 5 of 7 cases. In the last case, with a 50 per cent increase in efferent arteriolar resistance (if there is no technical failure) one would suspect either autonomous constriction of the efferent arteriole or a response to an increase in circulating adrenalin elicited by the fall of mean blood pressure to $\mathbf{7 5}$ $\mathrm{mm}$. Hg. (Normally, in the unanesthetized subject both arterioles appear to be active (6).)

\footnotetext{
'See Part II, The actual application of Poiseuille's law.

- In 2 cases under spinal anesthesia with extremely abnormal blood pressures of 64 and $75 \mathrm{~mm}$. $\mathrm{Hg}$, the formula for afferent resistance breaks down, becoming negaitive. This would indicate that in this circumstance intracapsular and intrarenal pressures are less than the values we have used as normal. A modification of these quantities so that the intracapsular urinary perfusion pressure remains $10 \mathrm{~mm}$. $\mathrm{Hg}$ would leave efferent arteriolar resistance unchanged, while increasing afferent arteriolar resistance and, to a much lesser extent, total arteriolar resistance.
} 
TABLE I

Effects of spinal anesthesia on renal arteriolar resistance*

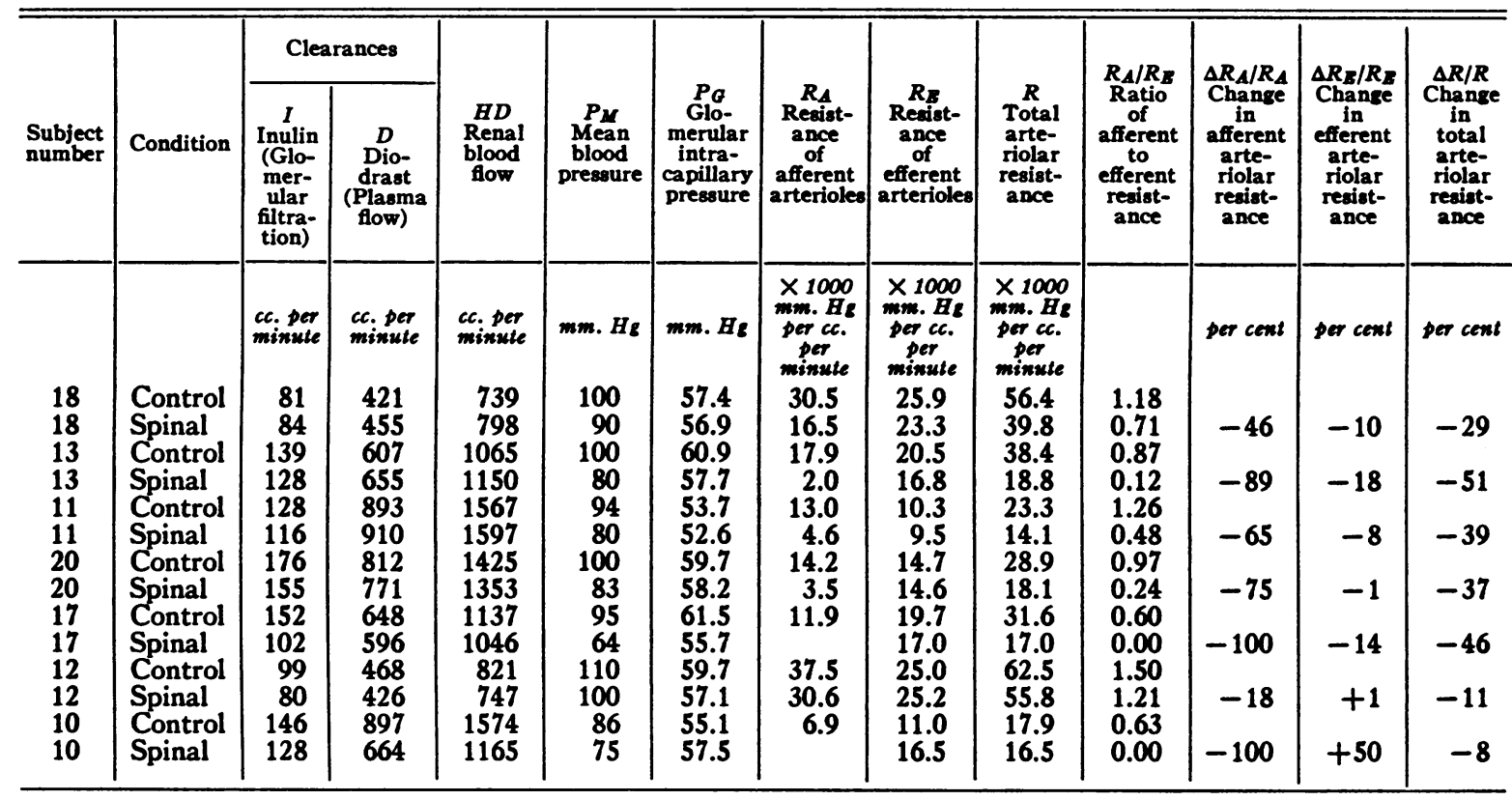

* See footnote 3 in text.

If we compute the average of the ratios to mean blood pressure of the blood pressure in the terminal portion of the glomerular capillaries $\left(P_{G}=P_{0^{\prime}}+20\right.$, see Part II) in the cases during anesthesia (renal denervation), we find a ratio of 0.70. If the 2 cases with abnormally low blood pressures are omitted, the ratio is $\mathbf{0 . 6 6}$. Winton and his collaborators report an average value of 0.66 (7) in the dog's isolated (denervated) kidney.

\section{PART II}

\section{FORMULAE FOR GLOMERULO-DYNAMICS}

\section{Glomerular equilibrium}

Smith et al. (2) first consider the relationship between the forces acting in the glomerulus. They reach the conclusion that, even under the condition of greatest renal blood flow, equilibrium exists between the difference in hydrostatic pressures on both sides of the glomerular membrane and the osmotic pressure of the concentrated blood before it leaves the glomerulus.

\section{The change in hematocrit during glomerular filtration}

Using the methods of Van Slyke (8), it can be shown that even during maximal glomerular hemoconcentration, when the plasma proteins are concentrated 33 per cent (2), the resulting change in $\mathrm{pH}$ of the plasma (neglecting the buffering action of the red cells) is less than 0.006 , which is less than the change occurring in the lungs. The hematocrit, with so small a shift, changes less than 1 per cent $(9,10)$. Consequently, in considering the effect of glomerular filtration on the red cells, the change in $\mathrm{pH}$ can reasonably be neglected.

We shall turn to the effect of the increase in plasma protein concentration on the red cells. While this increase is quite significant with respect to the glomerular membrane, which is permeable to all the crystalloid ions, it becomes insignificant so far as the red cell is concerned.

Recent studies using radioactive salts (11) have confirmed the previous finding that, in man, the red cell is, at least for a few hours, impermeable to sodium and potassium. The determination of the forces acting on the red cell membrane must, therefore, include the oncotic action of the impermeable crystalloid ions (sodium and potassium), as well as the protein, on both sides of the red cell surface." On this basis, a rough compu-

\footnotetext{
- We are very much indebted to Dr. Homer W. Smith
} for calling this fact and its implication to our attention. 
tation shows that plasma proteins account for only 1 per cent of the oncotic pressure of the plasma with respect to the red cell. Since the crystalloid ions permeate the glomerular membrane, they are not concentrated in the glomeruli and an increase of 33 per cent in plasma protein will produce a change of less than $1 / 3$ per cent in the oncotic pressure acting on the red cells. Such a change is, of course, trivial so that we are justified in concluding that little, if any, water leaves the red cells during glomerular filtration and that their absolute volume remains fixed. A formula based on this premise is easily derived and is presented later when the change in viscosity of the blood during its passage through the kidney is considered.

\section{Osmotic pressure of concentrated blood}

Since the red cells are not osmotically active in the ultrafiltration occurring in the glomerulus, they can be excluded while this problem is examined.

To apply the results of in vitro determination of the osmotic pressure of blood to the kidney, one must be sure that the glomerular membrane acts like the artificial membranes in use. There appears to be little difference among the artificial membranes (12) and a suggested electrical charge on the glomerular membrane (13) seems unlikely and unimportant $(14,15)$. The observations on human transudates by Loeb, Atchley, and Palmer (16) under in vitro conditions showed the similarity between the living and artificial semipermeable membrane and it therefore appears very likely that the results of laboratory determinations of osmotic pressure can be applied to glomerular ultra-filtration.

Excellent osmotic pressure measurements of blood have been made with an instrument invented by Hepp $(10,17,18)$. It has not, as yet, been applied to human blood or blood more concentrated than normal-the range we are concerned with - so that, in determining the relationship between osmotic pressure and protein concentration in human plasma, we shall use the recent results of Adair and his coworkers (19). They have studied the osmotic pressure of fresh and redissolved dehydrated human serum up to, but not beyond, normal concentration and have given an empirical formula. At the maximum glomerular hemoconcentration of 33 per cent, the osmotic pressure is found to be increased 65 per cent, so that the assumption by Smith et al. (2) of proportionality between osmotic pressure and protein concentration can lead to considerable error (20 per cent).

The Adairs' and Greaves' (19) formula, modified for $37.5^{\circ} \mathrm{C}$., is: $P_{o^{\prime}}=\frac{2.34 S^{\prime}}{1-0.0543 S^{\prime}}+0.1$, where $P_{o^{\prime}}$ is the osmotic pressure in $\mathrm{mm}$. of $\mathrm{Hg}$ of one source of normal human plasma and $S^{\prime}$ is the concentration of protein in grams per $100 \mathrm{cc}$. solution of the corresponding serum. The added number, 0.1, is derived from Hepp's work on cow's blood. The osmotic pressure of plasma is about $13 \mathrm{~mm} . \mathrm{H}_{2} \mathrm{O}$ less than that of the corresponding serum (17). But the osmotic pressure at $\mathrm{pH} 7.4$ (arterial blood) is about $141 / 2 \mathrm{~mm}$. of $\mathrm{H}_{2} \mathrm{O}$ greater than at $\mathrm{pH} 6.9$, the value studied by Adair. The difference, $11 / 2 \mathrm{~mm} . \mathrm{H}_{2} \mathrm{O}$, is $0.1 \mathrm{~mm}$. $\mathrm{Hg}$. Since this is less than $1 / 2$ per cent of $P_{O^{\prime}}$, it will be neglected. We then have:

$$
P_{o^{\prime}}=\frac{2.34 S^{\prime}}{1-0.0542 S^{\prime}}
$$

This formula is to be used to obtain the osmotic pressure of plasma at any degree of hemoconcentration.

\section{Intracapsular and intrarenal pressure}

In the glomerulus, let us call the hydrostatic pressure of the blood, when it reaches osmotic equilibrium with its filtrate, $P_{G}$, expressed in $\mathrm{mm} . \mathrm{Hg}$, and correspondingly let $P_{c}$ be the intracapsular pressure, the pressure against which the filtrate is formed. Smith et al's (2) description of equilibrium in the terminal capillaries of the glomerulus gives the equality:

$$
P_{G}=P_{o^{\prime}}+P_{C} .
$$

Is the intracapsular pressure the same as intrarenal pressure, which, in the dog, has been estimated to average $10 \mathrm{~mm} . \mathrm{Hg}$ and to be independent of arterial pressure $(20,21,22)$ ? Smith and his coworkers, in their analysis of the blood flow in and out of the glomerulus, assume that $P_{C}=P_{R}$. In such a circumstance, glomerular filtrate might conceivably be perfused through the tubules up to the loop of Henle where it be- 
comes osmotically concentrated (1), in part by diffusion from a high to a low concentration of water. But it is doubtful that this would be at all a potent factor, and certainly its effect would be reversed during the secretion of hypotonic urine found at times in all mammals (1). Another possibility is the suction effect of the absorption of about 99 per cent of the filtrate (1) by the time the urine has reached the first part of the distal tubule. Its result would be to make a suction pump out of the proximal tubules, loop of Henle, and part of the distal tubules, the energy coming from the tubular epithelium. An objection to this notion is that the pump would have no valve; it would similarly suck urine backwards, up the collecting tubules, from the pelvis of the kidney. Neither of these hypotheses offers a force to move the concentrated urine through the last part of the distal and the collecting tubules. That the arterial pulsations of renal tissue milk urine towards the calices because the resistance of the remote retrograde branches of the system is greater than that of the central trunks seems a minor likelihood, incapable of effectively explaining the perfusion of urine through distal and collecting tubules. We are forced to the conclusion that $P_{C}>P_{R}$; intracapsular pressure is greater than interstitial renal pressure.

O'Connor (23) calculated the glomerular filtrate perfusion pressure in the rabbit $\left(P_{C}-P_{R}\right)$ to be a minimum of $10 \mathrm{~mm} . \mathrm{Hg}$ if the bore of the tubules were $10 \mu$. In view of the fact that "histological sections would indicate a rather higher value" for the lumen (24), and because we have noted other factors helping in perfusion, we should choose this minimum value for human filtrate perfusion pressure: $P_{C}-P_{R}=10$. With Winton's average for interstitial pressure $\left(P_{R}\right.$ $=10 \mathrm{~mm} . \mathrm{Hg}$ ), we have: $P_{C}=20 \mathrm{~mm} . \mathrm{Hg}$; and $P_{G}=P_{o^{\prime}}+20$.

\section{Poiseuille's law}

Ideally, the resistance of a fixed tubular system to the flow of liquid is a constant defined by the ratio of the pressure difference used to perfuse it to the product of the rate of flow thereby produced and the relative viscosity of the fluid with respect to some standard. Inflow and outflow at the points of pressure measurement must be equal for the definition of resistance to apply.

$$
\text { Resistance }=\frac{\text { Perfusion pressure }}{\text { rate of flow } \times \text { relative viscosity }} .
$$

Experimental in vivo confirmation of this relationship, somewhat modified for the kidney, is crude (21). Perfusion experiments have shown that, while it applies with modification (a constant is subtracted from pressure) to the isolated hind-limb of the dog (25), it does not apply to the isolated dog's kidney (26). However, the isolated dog's kidney behaves quite differently, in certain respects, from the kidney in the anesthetized or unanesthetized dog. Its urine is hypotonic; its inulin clearance (glomerular filtration rate) is quite considerably lower (more than 50 per cent); its creatinine clearance is not uniformly proportional to inulin clearance (27). While, in man, inulin clearance is approximately independent of renal blood flow (2), in the isolated or anesthetized dog's kidney, this is not the case (27). The mechanism of dilution diuresis also appears to differ in the isolated and anesthetized kidney (28).

The presumption attending the application of Poiseuille's law to an isolated organ is that its resistance remains constant while the flow and the perfusion pressure which cause it vary. If the isolated organ's arterioles respond autonomously to the change in pressure, and the denervated anesthetized kidney, unlike the extremities, appears to do so $(29,30)$, this presumption would be false. It does not seem unreasonable, therefore, to apply Poiseuille's law to man's intact kidney. Smith and his coworkers have done so, without the modification found necessary in the hind-limb (25), analyzing separately afferent and efferent arteriolar resistance. We shall proceed with this analysis.

\section{Resistance of afferent arterioles}

Since the blood undergoes no change in viscosity before the glomerulus, no correction for viscosity is needed if only the afferent arteriolar resistance referred to normal blood is measured. However, the two points of pressure reference chosen by Smith et al. are average arterial pressure and hydrostatic blood pressure in the glomerulus when osmotic equilibrium with ultra- 
filtrate is reached, which must be near the efferent arteriole.

We can consider afferent resistance defined in this way $\left(R_{A}\right)$ to be composed of true afferent arteriolar resistance, ending at Bowman's capsule $\left(\bar{R}_{A}\right)$ and the resistance of the glomerular capillaries $\left(R_{G}\right)$ to perfusion $\left(R_{P}\right)$ and filtration $\left(R_{\boldsymbol{r}}\right)$. Thus, we would have:

$$
R_{A}=\bar{R}_{A}+R_{G} .
$$

Since the filtration and perfusion resistances of the capillaries are parallel, they are computed in the usual way:

$$
\frac{1}{R_{G}}=\frac{1}{R_{P}}+\frac{1}{R_{F}}
$$

It is found that, at the mean basal plasma filtration fraction of 19 per cent (2), where the effect of changes in viscosity of perfused blood and filtered plasma (they are opposite in direction and tend to cancel) are neglected, the result of computing $R_{G}$ with the above formula, using Poiseuille's law, is less than 11 per cent different from the result when we compute $R_{G}$ as:

$$
R_{G}=\frac{\text { fall in pressure in glomerular capillaries }}{\text { rate of flow of blood into glomerulus }} .
$$

While an error of 11 per cent in $R_{G}$ may seem considerable, it is relatively small in its effect on $R_{A}$, as defined above to include $R_{G}$, since $R_{G}$ is small compared with $\bar{R}_{A}$; the pressure drop in the glomerulus itself is small compared with that in the afferent arteriole. ${ }^{5}$

By the time the blood in the glomerular capillaries reaches the efferent end, its volume has been diminished by filtration and its viscosity has increased due to the increase in the hematocrit and the concentration of plasma protein. In Poiseuille's law, the denominator of the expression for resistance is the product of flow and viscosity. Since flow decreases and viscosity increases, the effects of the two errors in neglecting these changes are in opposite directions. Later, in the consideration of the efferent arteriolar resistance, it will be shown that these errors almost cancel each other. It is for this reason, as well as because $R_{G}$ is small compared with

\footnotetext{
- The change of kinetic into potential energy is negligible (31).
}

$\bar{R}_{A}$, that we introduce little error in computing $R_{A}$ up to the equilibrium point in the glomerular capillaries, near the efferent arterioles, without allowing separately for filtration resistance, reduced flow, and increased viscosity. Smith and his associates likewise make the same choice, including the glomerulus in afferent arteriolar resistance without special adjustment (2).

\section{Resistance of efferent arterioles}

The problem of the efferent arteriole is different in that in it the blood viscosity is increased throughout the major fall of pressure, up to the point where the glomerular filtrate has been reabsorbed in the peritubular capillaries. Smith and his coworkers make no allowance for the increase in viscosity since they consider it negligible (2).

\section{Effect of change in viscosity}

Let us compute the importance of this change to ascertain how large a factor it is.

It has been shown that the viscosity of blood depends on the hematocrit, but that it is also proportional to the viscosity of the plasma $(32,33)$. The maximum plasma protein concentration observed by Smith and his associates is 33 per cent (2), so we are interested in the range of plasma viscosity from 7 grams per cent (taken as normal) to 9.3 grams per cent. While there have been many attempts to offer general formulae relating the concentration of solute to viscosity, none has been completely successful. However, in our range, a simple linear relationship is an excellent empirical one $(34,35)$. Such a formula, based on the data for serum viscosity in the proper range (35), has been derived by the method of least squares, modified with an increase of $22 \mathrm{I} / 2$ per cent at normal hemoconcentration to obtain the viscosity of the corresponding plasma $(36,37)$. Where $V^{\prime}$ is relative viscosity of the corresponding plasma with reference to water as unity, and $S^{\prime}$ is defined as previously for osmotic pressure, we obtain:

$$
V^{\prime}=0.60+0.204 S^{\prime}
$$

We must now compute the change in hematocrit caused by glomerular filtration.

Let $H_{c}=$ hematocrit of blood before ultrafiltration. $H_{c}^{\prime}=$ hematocrit of blood after ultrafiltration. 
$D=$ diodrast clearance of plasma in cc. per minute corrected for incomplete renal extraction and residue in red cells (2) (rate of flow of plasma through kidney).

$I=$ inulin clearance in cc. per minute (2) (rate of glomerular filtration by the kidney).

$F=\frac{I}{D}$, filtration fraction.

The new hematocrit is found:

$$
H_{c}{ }^{\prime}=\frac{\text { unchanged volume of } \mathrm{RBC}}{\begin{array}{c}
+ \text { volume of } \mathrm{RBC}+\text { initial volume of plasma } \\
\text { vegree of increased plasma concentration }
\end{array}}
$$

Or,

$$
H_{c}^{\prime}=\frac{H_{c}}{H_{c}+\left(1-H_{c}\right)(1-F)} .
$$

On this basis, with $F$ at its maximum value of 0.33 , and taking a high initial hematocrit of 60 per cent, we find that $H_{c}^{\prime}$ is 69 per cent. Consequently, we are interested in a range of hematocrit from about 35 to 70 per cent. The effect of hematocrit on the viscosity of blood in the dog has been carefully studied by Whittaker and Winton (25). Using their curve (p. 358) in this range, we have obtained an excellent fit with the following empirical equation:

$$
U^{\prime}=\frac{V^{\prime}}{V}\left(0.27+\frac{0.983}{1-H_{c}^{\prime}}\right) \text {. }
$$

Here $U^{\prime}$ is the viscosity of whole blood of hematocrit $H_{c}{ }^{\prime}$ and plasma viscosity $V^{\prime}$, while $U$ and $V$ are the values for unconcentrated normal blood $\left(H_{c}^{\prime}=H_{c} ; V^{\prime}=V\right)$.

Formulae have been given for all the quantities determining $U^{\prime}$ so that we can compute the relative change caused by glomerular filtration. We use for the normal hematocrit $\left(H_{c}\right)$ Smith's average value of 43 per cent. ${ }^{1}$

The maximum increase in blood viscosity occurs when the filtration fraction is 33 per cent. In this case, with relative viscosity entering into the denominator of Poiseuille's law, efferent arteriolar resistance would be estimated at the most 46 per cent too high, if the increase in blood viscosity caused by glomerular filtration is neglected. But if the loss of glomerular filtrate is also disregarded in estimating efferent arteriolar flow, along with the increase in viscosity, the result is at the worst 118 per cent of the more exact value, an error of 18 per cent. We see, then, that if an approximation is to be made, it is wiser to neglect both the reduction in flow and the increase in viscosity of the blood in the efferent arteriole, rather than either one alone, since they tend to compensate each other. At mean basal plasma filtration fraction (19 per cent), these errors are considerably reduced$231 / 2$ per cent and 10 per cent, respectively. This illustrates in numerical form our previous statement that it is proper to neglect the opposing effects on resistance of changes in viscosity and blood flow occurring in the glomerulus when defining afferent arteriolar resistance. Strikingly enough, we see that the error introduced by this approximation for the resistance of the efferent arteriole is nearly proportional to the filtration fraction. Thus $0.47 F$ can be applied to correct our simplified formula for efferent resistance where the hematocrit is properly taken as the average, 43 per cent. Other factors of $F$ can be used for other values of the hematocrit, if need should arise. It may be noted that the more precise expression involving viscosity and reduced blood flow depends only on clinically measurable quantities. We have:

Efferent arteriolar resistance

$$
=\frac{\text { pressure difference } \times(1-0.47 F)}{\text { whole blood flow through kidney }} .
$$

\section{The definition of efferent arteriolar resistance}

The next step in the definition of efferent arteriolar resistance, having considered the changed viscosity and the reduced flow in this arteriole, is to consider what the perfusion pressure is. Certainly the equilibrium pressure at the efferent end of the glomerular capillaries, used as the terminal one in the definition of afferent resistance, is the correct initial one and we shall follow Smith et al. (2) in using it, although computing its value, as above, somewhat differently. The ideal terminal pressure would be the one at the arterial end of the peritubular capillaries, before significant change in the rate of blood flow due to reabsorption of the glomerular filtrate has occurred. But this pressure is not known and is certainly a variable one, depending on rate of flow and other factors, so that a fixed estimate of its size is unwarranted. As the blood 
passes through the capillaries to the venules, ${ }^{6}$ its volume is restored to 99 per cent of its original value by the reabsorbed glomerular filtrate and its viscosity falls back to normal. This is roughly the reverse of the situation in the glomeruli. By choosing venous capillary pressure as our terminal pressure in the definition of efferent arteriolar pressure, we introduce an error, but once again the effects of falling viscosity and rising flow are in opposite directions; the fraction involved of the total efferent arteriolar resistance defined is small, and so the net effect can be neglected. Homer Smith and his coworkers (2) have similarly chosen for their terminal perfusion pressure the venous end of the capillaries where hydrostatic blood pressure is very likely to be approximately equal to the sum of intrarenal and normal osmotic pressures. We shall, therefore, chose $P_{R}+P_{O}$, where $P_{O}$ is normal blood osmotic pressure in $\mathrm{mm}$. $\mathrm{Hg}$, for the terminal pressure in our definition of efferent arteriolar resistance.

\section{Arterial pressure}

In measuring the perfusion pressure of the afferent arteriole, we should naturally choose the pressure in the renal artery. Since this is pulsatile, the best approximation would be its integrated mean value. This value is not the average of systolic and diastolic blood pressure but diastolic blood pressure plus 44 per cent of the pulse pressure (38). The fall in this more precise mean, as obtained from subclavian and femoral arteries in man, is usually about $2 \mathrm{~mm}$. of mercury. The average of systolic and diastolic pressure is about $3 \mathrm{~mm}$. $\mathrm{Hg}$ too high (38). It is therefore clear that the average of systolic and diastolic blood pressure taken at the arm is a good enough measure of mean renal artery pressure.

\section{The actual application of Poiseuille's law}

Previously, we have mentioned Whittaker and Winton's (25) finding that Poiseuille's law applies to the hind-limb of the dog perfused with blood, but with modification. They find that the perfusion pressure plotted against the flow is a straight line with an intercept at about $20 \mathrm{~mm}$. of

\footnotetext{
- The cortical tissues are mainly nourished by glomerular filtrate on its way to the capillaries.
}

mercury. That is to say, Poiseuille's law for blood is really:

$$
\text { Resistance }=\frac{\text { Perfusion pressure }-20}{\text { Rate of flow }} .
$$

This phenomenon appears to be an inherent one of blood itself (25). There is further confirmation of it in the intact animal (39). In applying Poiseuille's law to the afferent arteriole, we shall therefore use this $20 \mathrm{~mm}$. $\mathrm{Hg}$ correction. But we shall not use it in the efferent arteriole where blood flows from capillaries back to capillaries, not from artery to capillaries, as in the afferent arteriole and in Whittaker and Winton's experiments.

We are now ready to utilize Smith and his coworkers' (2) analysis of renal dynamics as modified above.

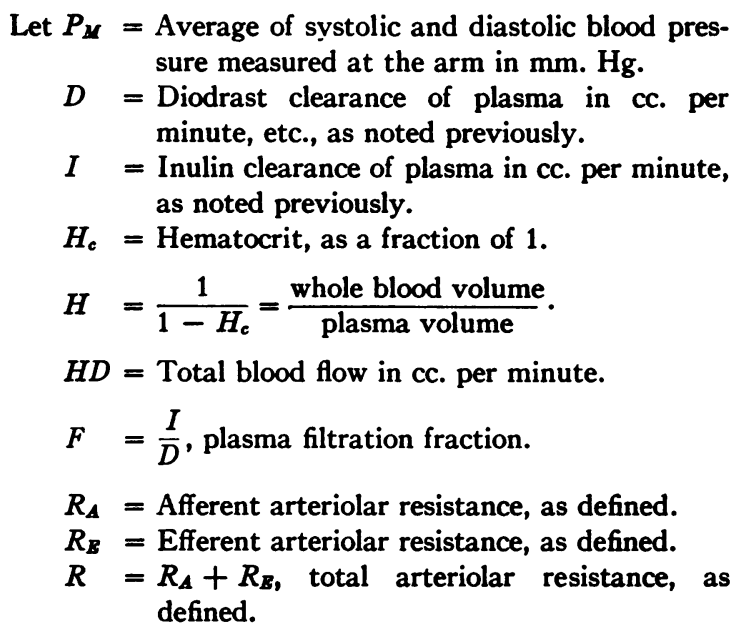

The resistance units will be $\mathrm{mm}$. $\mathrm{Hg}$ per cc. per minute with the viscosity of the unconcentrated blood take as unity.

Other symbols have already been defined.

The perfusion pressure for the definition of afferent arteriolar resistance is the difference between mean renal artery pressure and the equilibrium blood pressure in Bowman's capsule. Thus:

$$
R_{A}=\frac{P_{M}-P_{G}-20}{H D}
$$

The perfusion pressure for $R_{E}$ is $P_{G}$ - $\left(P_{O}+P_{R}\right)$; the flow is $H D-I$. We have:

$$
R_{E}=\frac{P_{G}-P_{O}-P_{R}}{(H D-I) \frac{U^{\prime}}{U}}
$$


Substituting for $P_{G}$ its equivalent, $P_{c}+P_{o^{\prime}}$, we write:

$$
R_{E}=\frac{P_{O^{\prime}}-P_{o}+10}{(H D-I) \frac{U^{\prime}}{U}} .
$$

We have justified the substitution, where $k$ is a constant dependent on the hematocrit,

$$
(H D-I) \frac{U^{\prime}}{U}=\frac{H D}{1-k F} \text {. }
$$

Accordingly,

$$
\begin{gathered}
R_{E}=\frac{(1-k F)\left(P_{O^{\prime}}-P_{O}+10\right)}{H D} ; \\
R_{A}=\frac{P_{M}-P_{o^{\prime}}-40}{H D} .
\end{gathered}
$$

The formula for $\boldsymbol{P}_{o^{\prime}}$ has already been given (see Equation (1)), and $P_{o}$ is found from this formula when for $S^{\prime}$ we substitute $S$, the clinically observed value for unconcentrated serum protein. The degree of hemoconcentration being $\frac{1}{1-F}$, we have $S^{\prime}=\frac{S}{1-F}$.

Substituting the formula for $S^{\prime}$ in that for $P_{O^{\prime}}$, we find that:

$$
P_{o^{\prime}}=\frac{2.34 S}{1-0.0542 S-F} .
$$

$P_{o}$ is the value of $P_{o^{\prime}}$ when $F$ is set equal to zero.

Equations (6) and (7) for $R_{E}$ and $R_{A}$ are therefore seen to be completely determined, with the aid of Equation (8), by the clinically determinable entities: serum protein, hematocrit, inulin and diodrast clearances, and blood pressure. ${ }^{7}$

\section{SUMMARY}

The application of Poiseuille's law to the kidney has been discussed and formulae have been developed to measure clinically, in man, afferent and efferent arteriolar resistance. A practical application to available clinical data on the renal effect of spinal anesthesia (denervation) in normal man has also been offered. At present, while normal man may lack tonic central nervous control of renal blood flow, this does not

\footnotetext{
'The method of computing $k$ has already been given under Effect of change in viscosity. Usually, $k=0.47$ is adequate, as most hematocrits are near $\mathbf{4 3}$ per cent.
}

appear to have been demonstrated. The evidence also does not preclude autonomous control by the kidney of its blood supply.

Incidentally, empirical formulae for the viscosity of human plasma and whole blood have been derived from observations in the literature.

\section{BIBLIOGRAPHY}

1. Smith, H. W., Physiology of the Kidney. Oxford Univ. Press, New York, 1937.

2. Smith, H. W., and others, Glomerular dynamics in normal human kidney. J. Clin. Invest., 1940, 19, 751.

3. Smith, H. W., and others, Effects of spinal anaesthesia on circulation in normal, unoperated man with reference to autonomy of arterioles, and especially those of renal circulation. J. Clin. Invest., 1939, $18,319$.

4. Goldfarb, W., Provisor, B., and Koster, H., Circulation during spinal anaesthesia. Arch. Surg., 1939, 39, 429.

5. Lamport, H., Unpublished.

6. Lamport, H., The relative changes in afferent and efferent arteriolar resistance in the normal human kidney. J. Clin. Invest., 1941, 20, 545.

7. Eggleton, M. G., Pappenheimer, J. R., and Winton, F. R., The relation between ureter, venous, and arterial pressures in the isolated kidney of the dog. J. Physiol., 1940, 99, 135.

8. Van Slyke, D. D., Factors Affecting the Distribution of Electrolytes, Water, and Gases in the Animal Body. Lippincott, Philadelphia, 1926.

9. Van Slyke, D. D., Wu, H., and McLean, F. C., Studies of gas and electrolyte equilibria in blood. V. Factors controlling electrolyte and water distribution in blood. J. Biol. Chem., 1923, 56, 765.

10. Hepp, O., Uber den Einfluss der Temperatur und der Kohlensaürenspannung auf den kolloidosmotischen Druck von Serum und Blut. Ztschr. f. Biol., 1938, 99, 230.

11. Eisenman, A. J., and others, Study of permeability of human erythrocytes to potassium, sodium, and inorganic phosphate by use of radioactive isotopes. J. Biol. Chem., 1940, 135, 165.

12. Turner, A. H., Validity of determinations of colloid osmotic pressure of serum. J. Biol. Chem., 1932, 96, 487.

13. Keller, R., Der Elektrische Faktor der Nierenarbeit. Nachfolger, Mährisch-Ostran, 1933.

14. Cori, M., Richerche sulla pressione oncotica del siero. Riforma med., 1929, 45, 383.

15. Von Farkas, G., in Bennhold, H. H., et al, Die Eiweisskörper des Blutplasmas, Steinkopff, Dresden, 1938.

16. Loeb, R. F., Atchley, D. W., and Palmer, W. W., Studies on regulation of osmotic pressure. II. Effect of increasing concentrations of albumin on conductivity of a sodium chloride solution. J. Gen. Physiol., 1922, 4, 585.

17. Hepp, O., Ein neues Onkometer zur Bestimmung des 
kolloidosmotischen Druckes mit gesteigerter Messgenauigkeit und vereinfachterHandhabung. Ztschr. f. d. ges. exper. Med., 1936, 99, 709.

18. Peters, E., and Saslow, J., Performance of Hepp microosmometer. J. Gen. Physiol., 1939, 23, 177.

19. Adair, G. S., Adair, M. E., and Greaves, R. I. N., Osmotic pressure, after re-solution, of serum, dried from frozen state (F. D. serum). J. Hyg., 1940, 40, 548.

20. Winton, F. R., Intrarenal pressure. J. Physiol. (Proc.), 1937, 78, 9.

21. Herman, F. G., and Winton, F. R., The interaction of intrarenal and extrarenal pressures. J. Physiol. (Proc.), 1936, 87, 77.

22. Winton, F. R., The influence of changes in arterial pressure on the intrarenal pressure in the isolated mammalian kidney. J. Physiol., 1936, 87, 18.

23. O'Connor, J. M., Glomerular control of kidney blood flow. J. Physiol., 1924, 59, 200.

24. O'Connor, J. M., and McGrath, J. A., Localization of excretion in uriniferous tubule. J. Physiol., 1924, 58, 338.

25. Whittaker, S. R. F., and Winton, F..R., Apparent viscosity of blood flowing in isolated hind limb of dog, and its variation with corpuscular concentration. J. Physiol., 1933, 78, 339.

26. Winton, F. R., The rate of production of glomerular fluid compatible with the changes of blood flow and blood viscosity with arterial pressure in the dog's kidney. Trans. XIV Congresso Internaz. de Fisiol., 1932, p. 264.

27. Shannon, J. A., and Winton, F. R., Renal excretion of inulin and creatinine by anaesthetized dog and pump-lung-kidney preparation. J. Physiol., 1940, 98, 97.
28. Eggleton, M. G., Pappenheimer, J. R., and Winton, F. R., Mechanisms of dilution diuresis in isolated kidney and anaesthetized dog. J. Physiol., 1940, 98, 336.

29. Hartmann, H., Ørskov, S. L., and Rein, H., Die Gefässreaktionen der Niere im Verlaufe allgemeiner Kreislauf-Regulationsvorgänge. Pfüger's Arch., 1936, 238, 239.

30. Opitz, E., and Smyth, D. H., Nierendurchblutung bei Reizung des Carotis Sinus. Pflüger's Arch., 1937, 238, 633.

31. White, H. L., Glomerular filtration. Am. J. Physiol., 1924, 68, 523.

32. Trevan, J. W., The viscosity of blood. Biochem. J., $1918,12,60$.

33. Brundage, J. T., Blood and plasma viscosity determined by method of concentric cylinders. Am. J. Physiol., 1935, 110, 659.

34. Chick, H., and Lubrzynska, E., The viscosity of some protein solutions. Biochem. J., 1914, 8, 59.

35. Hellwig, A., and Neuschlosz, S. M., Zur funktionellen Schilddrüsendiagnostik. Klin. Wchnschr., 1922, 1, 1988.

36. Neuschlosz, S. M., Die Viscosität des Blutes. Handbuch der normalen und pathologischen Physiologie. Springer, Berlin, 1928, vol. 6, p. 619.

37. Klinke, K., in Lichtwitz, L., Liesegang, R. E., and Spiro, K., Medizinische Kolloidlehre, Steinkopff, Dresden, 1935, p. 383.

38. Böger, A., and Wezler, K., Die Bestimmung des arteriellen Gesamtwiderstandes am Menschen. Arch. f. Exper. Path. u. Pharmakol., 1937, 186, 43.

39. Dow, P., and Hamilton, W. F., Analysis of emptying segments of arterial reservoir. Am. J. Physiol., 1939, 127, 785. 